\title{
Digitalization of logistics hubs as a competitive advantage of logistics networks
}

\author{
Irina Kapustina ${ }^{1}$, Vladimir Bakharev ${ }^{1}$, Sergei Barykin ${ }^{1 *}$, Egor Kovalenko ${ }^{2}$, and Kseniya \\ Pasternak $^{3}$ \\ 1, Peter the Great St. Petersburg Polytechnic University, Polytechnicheskaya, 29, St. Petersburg, \\ 195251, Russian Federation \\ ${ }^{2}$ Saint Petersburg State Maritime Technical University, Lotsmanskaya Ulitsa, 10, St. Petersburg, \\ 190121, Russian Federation \\ ${ }^{3}$ National Research University Higher school of Economics, Saint-Petersburg branch, Str. \\ Kantemirovskaya, 3A, St. Petersburg, 194100, Russian Federation
}

\begin{abstract}
The article reveals the concept of a logistics unit, logistics and digital hubs. The aim of the study is to assess the competitive prospects for digitalization of the Russian logistics block of the Northern Sea and New Silk ways as a set of international logistics and digital hubs, as well as exhibition complexes and educational sites. The research is focused on combining the logistics sections of the Northern Sea Route and the New Silk way into a single logistics system with its further registration in digital space. The main goal of this system is to unite all available resources of the Russian Federation in its block of the international logistics system to attract the largest number of partners and customers. It is considering the possibility of combining the Northern Sea and New Silk way sections into a single system on the territory of the Russian Federation. The authors investigated the ways of digitalization of the logistics block of the NSR-NSW with the subsequent creation of a virtual space for the control and redistribution of trade throughout the Russian Federation. During the research, studies were conducted in the field of public administration, which use modern digital communications and digital security systems. Possibilities of implementing a system of digital hubs based on the results. As a result of the study, potential positive results from the implementation of the project of digital inter-hub networks in both the economic and social sectors were highlighted.
\end{abstract}

\section{Introduction}

The article considers the formation of a competitive advantage based on the digitalization of logistics hubs of the Northern Sea route (NSR) and the New Silk way (NSR), which are transport routes that run through the territory under the jurisdiction of the Russian Federation and are part of the Intercontinental transport system.

The development of these routes has a positive potential in the development of economic complexes in the South-Eastern and Arctic regions, as well as will significantly increase the

\footnotetext{
* Corresponding author: sbe@ @ist.ru
} 
economic potential of the country. With the uniform development of NSR and NSW in the Russian regions, followed by integration into a single logistics block, it can lead to a significant synergistic effect [1]. Also, this project has a huge social and cultural potential in the field of training and Congress and exhibition activities.

At the moment, measures are already being taken to develop these priority routes, which include the reconstruction of old and implementation of new roads and railways, and the development of economic complexes in the Arctic region. The issue of creating logistics hubs and centers on these transport corridors, the essence of which is to maintain the smooth operation of routes and their integration into a single logistics block, is also actively discussed [2]. To formalize the design of cargo flows in the conditions of using the NSR-NSW logistics block, to ensure uninterrupted year-round cargo turnover in competitive terms with the possibility of urgent response to force majeure, it is necessary to define the conceptual apparatus for the formation of logistics hubs in both physical and digital embodiments. Implementation of logistics solutions for The New Silk way and the Northern Sea route, aimed at improving and optimizing the functioning of the transport system using digital technologies, is one of the priority directions of Russia's economic development until 2025 $[3]$.

\section{Materials and methods. The purpose of the study and conceptual model}

The aim of the study is to assess the competitive prospects for digitalization of The Russian logistics block of the Northern Sea route and the New Silk way as a set of international logistics and digital hubs, as well as exhibition complexes and educational platforms.

Under the concept of a logistics hub, we consider a set of logistics parks and multi-modal complexes designed for processing, checking, controlling, and redistributing cargo flows that are united by territory [4]. A digital hub is considered as an IT-block in a digitalized logistics system analysis and management system that is linked to a specific cell (physical hub) in the virtual space. A logistics block is defined as a part of an international logistics system that is divided by nationality, taking into account its territorial location (in this case, the Russian block is considered). The international logistics system should be understood as a set of blocks that forms an integral system aimed at administering and controlling material interstate flows, starting with the transportation of raw materials products, to the delivery of various combined cargoes to the final consumer [5].

Currently, we will focus on combining the logistics sections of the Northern Sea route and the New Silk way into a single logistics system with its further registration in the digital space. The main goal of this system is to combine all available resources of the Russian Federation in its own international logistics system to attract the largest number of partners and customers (Fig. 1).

This system has feedbacks that perform certain control and accounting functions and operations in the field of logistics. In the context of the North Sea - New Silk way, the logistics system is a set of sea routes and ports in the Arctic zone, railway tracks and stations in the Central-abscissive and southern-border zones of Russia, which are a transport corridor for Russia, Asia, Europe and the United States [6].

The increase in the intensity and mass transport circulation in the Russian logistics unit, as well as providing controlled by Russian Federation communication highways of Asia and Europe is a priority task of Russia, which can be solved by the development and optimization of logistics system NSR-NSW. 


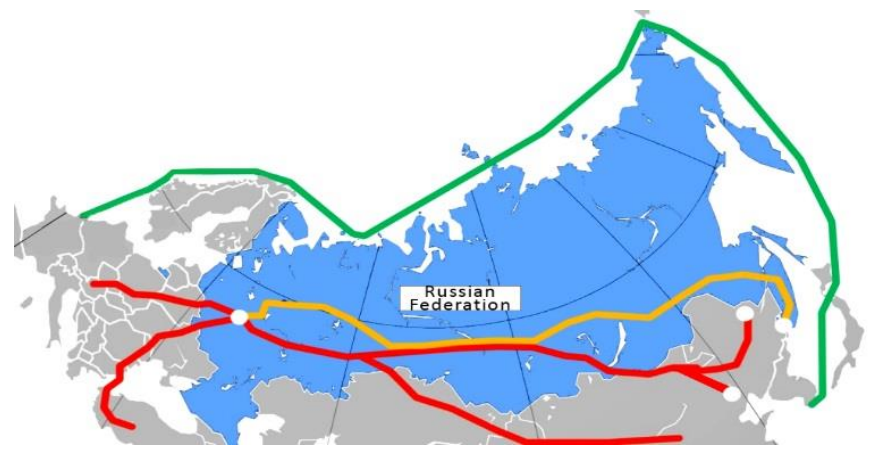

Fig. 1. Map of NSR-NSW routes on the territory of the Russian Federation.

Combining the sections of the Northern Sea route and the New Silk way that are under the jurisdiction of the Russian Federation into a single logistics and information block will lead to the possibility of redistributing goods transport flows between land and sea routes, depending on the need. This system will allow you to immediately respond to force majeure in the form of weather conditions, emergencies and congestion of checkpoints on the routes.

\section{Results}

The first stage, to ensure uninterrupted and timely response of this system, is to create so called digital hubs-digital spaces that fully reflect all the processes of real physical hubs in this logistics block. The digital database of hubs should display: the load of loading and unloading zones and warehouses, the average time-cost for processing a consignment, the capacity of customs posts, the schedule of shipments and arrivals of vehicles. It is also necessary to create an electronic document management system between the sender, recipient, carrier and customs authorities [7]. This system should allow you to remotely upload shipping invoices, invoices, contracts, transaction passports, product specifications, invoices, packing lists, certificates and other documents necessary for the legal transportation of a particular type of cargo (Fig. 2).

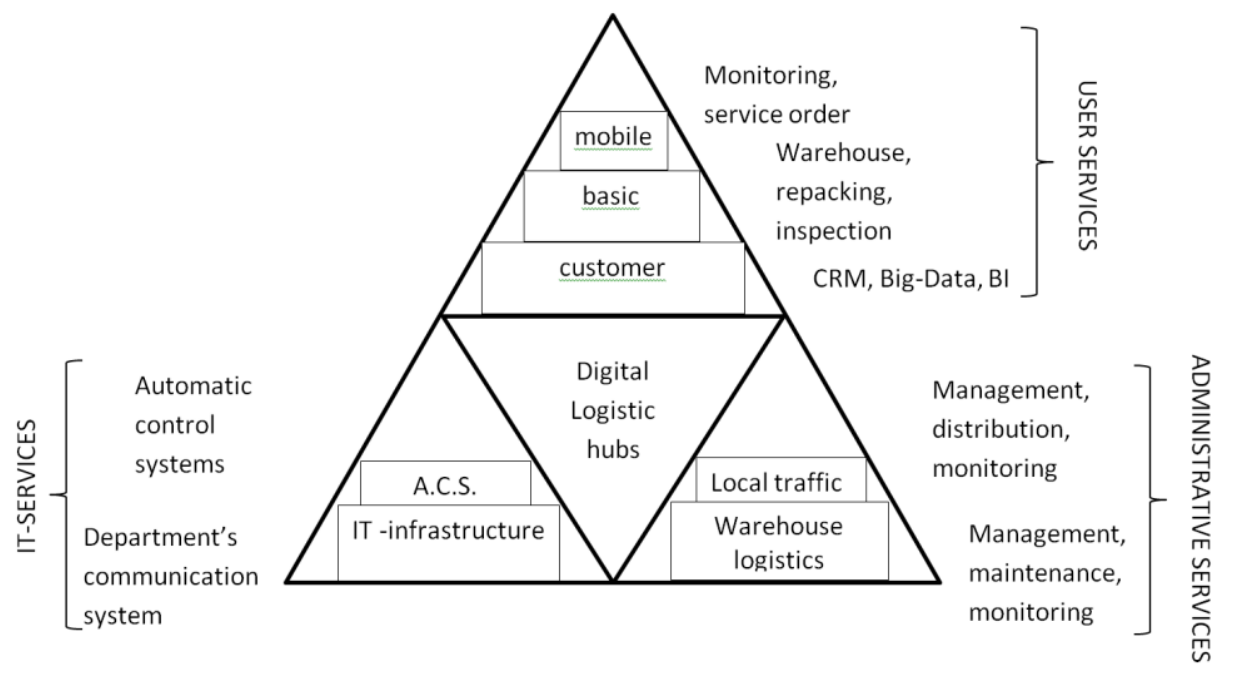

Fig. 2. Local architecture of the digital hub. 
In this case, it will be possible to remotely monitor the current and planned capacity of a particular hub, as well as the congestion of sea, rail and road routes - this measure will allow you to quickly adjust the previously planned route in the event of an oversaturation of one of the checkpoints or transshipment points (Fig. 3).

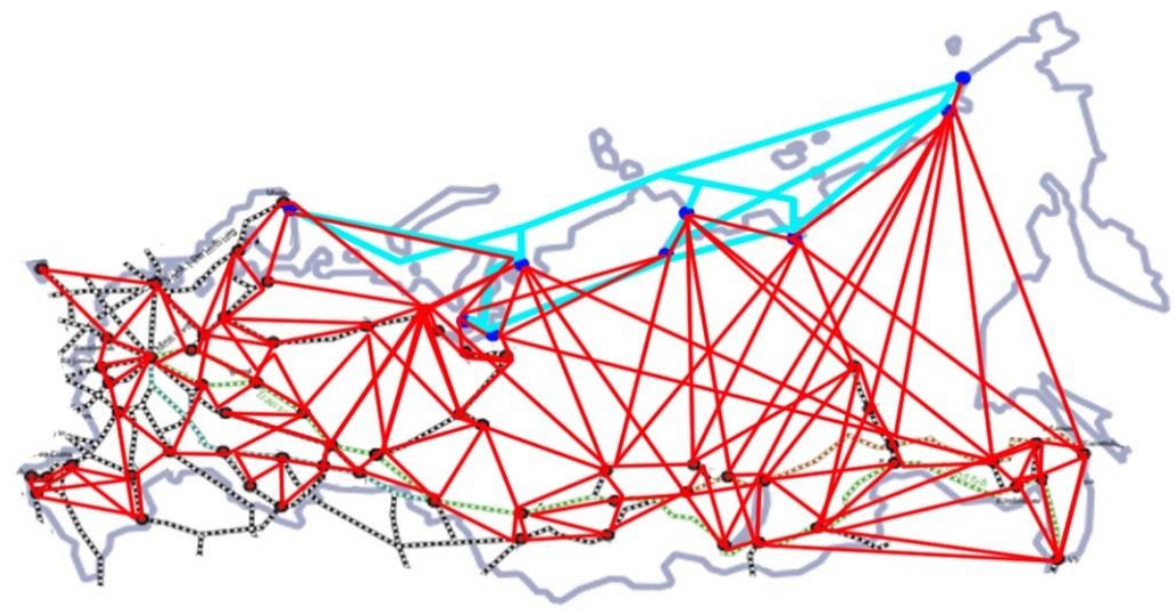

Fig. 3. Digital inter-hub network

At the third stage of digitalization of the logistics block, it is necessary to carry out a number of measures to integrate and modernize the software of the existing state procurementate apparatus into the inter-hub network [8]. Thus, this digital platform will add the possibility of remote conclusion of two-way smart contracts for the implementation of transportation between the customer (sender or recipient) and the contractor (logistics company), controlled by the state (Fig. 4).

After completing the inter-hub network connection, the system can gradually introduce digital offices-responsible for issuing certificates and certificates of authorities, with access to sections of the digital storage in accordance with their competencies. This measure will also speed up the document flow, which in turn will reduce the time spent on passing the path from the sender to the recipient [9].

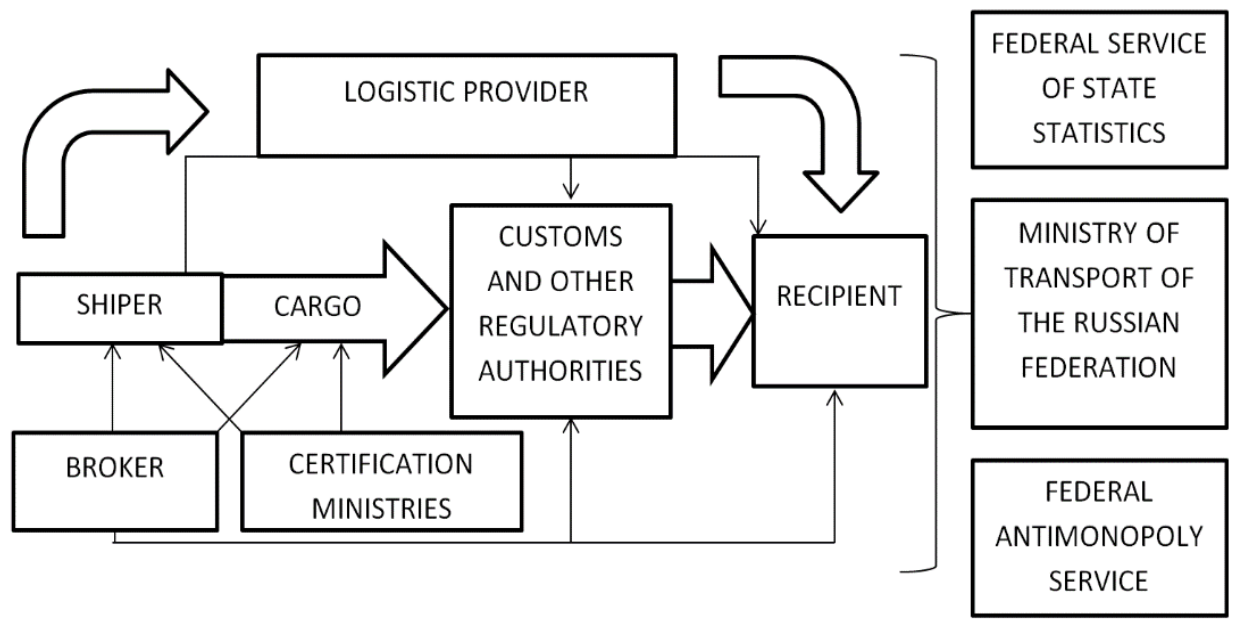

Fig. 4. Diagram of relationships between participants of the digital logistics platform.

The final step in the digitalization of the logistics block can be the connection of the 
access system to the blockchain technology. In contrast to the transfer of the entire data system to the blockchain, connecting only the access system requires less energy costs, while not inferior in terms of security. In this case, using the blockchain technology, all data about users of the unified logistics portal and their relationships will be placed in a closed, separate cloud storage with a single connection point - and without proper authorization in the block chain, access to it will be impossible. The obvious and most important advantage is the maximum protection of information from falsification. It is almost impossible to change the data after entering into the blockchain registers, which allows using them as full-fledged legally significant documents [10].

In addition to the undeniable economic effect, the system of interconnected hubs has social significance for the population:

- first, it is the collection of statistics and the ability to monitor practical solutions in an online format for students in the field of Economics, management and logistics.

- secondly, the creation and development of physical hubs is an influx of vacant jobs for specialists in both technical and humanitarian professions in completely different areas from IT-technologists to civil engineers. Also, hubs can be bases for practice and retraining.

It should be noted that cultural and exhibition complexes can be organized on the territory of the hubs for holding events of domestic and international level, such as congresses, technological and cultural exhibitions, festivals of science and culture, and various forums.

In the fifth, as the result of the above, perhaps the development of infrastructure hubs close to residential settlements, the development of hotel and restaurant business, open malls, increasing the number of retail outlets, as well as a General increase in the level of services provided [11].

\section{Discussion}

The implementation of the above list of measures can lead to the following positive results:

Shippers do not have to request commercial offers from carriers, for a long time identifying the most profitable ones for them, adjusting to the temporary corridors of various logistics companies. It will be sufficient to place an order for a certain number of cargo spaces, indicating the point of arrival of interest, the time fork and the type of cargo. After placing an order, it becomes available to all registered carriers -and carriers already offer their prices for the transportation of this cargo. In this version of the work, the order and registration of transportation services from logistics organizations is reduced to a system of auctions $\mathrm{n}$ reduction, where the customer acts as the contract holder, and carriers act as players fighting for customers. At the same time, it is possible to quickly complete container shipments for carriers [12].

The ability to quickly respond to changes in traffic density in any of the directions, with further redistribution of cargo vehicles on adjacent routes with online coordination of adjustments with the authorities supervising the routes. Also, in the future, these processes can be automated with proper software upgrades. Acceleration of the customs clearance process due to the fact that all necessary documentation is loaded into a single system before the shipment is sent. In this case, it is possible to avoid a huge number of paper carriers and automate the system of exchange and verification of documents by customs authorities as much as possible - which in turn offloads traffic on physical hubs. Simplification of the mechanism for collecting statistical data for each of the senders and carriers on the frequency and volume of traffic, types of cargo and popularity of destinations for public authorities. Also, based on statistical analysis, it is possible to forecast traffic taking into account the seasonal saturation of routes and weather conditions for the correct distribution of cargo flows along routes[13].

Based on the collected statistical data on carriers, it is possible to identify the main market 
players and control monopolization by subsidizing and allocating quotas for transportation. These measures will help maintain healthy competition in the market and promote national carriers. This data collection system can also be useful for the Ministry of defense of the Russian Federation. With advanced analysis of traffic congestion and the speed of passage of various routes by all modes of transport, it is possible to calculate the time spent on the transfer of military equipment not in a theoretical but applied format, which increases the country's defense capability. Not to mention monitoring the number and movement of vehicles owned by non-resident companies in the country.

\section{Conclusion}

Summing up, we can say that in this work, we have studied ways to digitalize logistics hubs, and presented options for combining them into a single logistics IT-network based on existing government platforms using blockchain technology. Positive results from this project were also revealed.

In conclusion, it should be said that the project of combining the two most important routes into a single logistics block, with its further digitalization and systematic transfer to the IT environment, is extremely profitable for our country and has a huge potential. Significant reduction of bureaucracy, practical elimination of paper document flow, significant reduction of transaction costs, full control over the activities of platform users, which allows timely disqualification of unscrupulous participants-all this provides a favorable environment for doing business. Thus, this project can significantly speed up cargo transportation processes both within the country and in the global logistics market - which will strengthen our country's position in the international arena and increase its attractiveness as a global transit zone between Eastern and Western countries compared to alternative routes. In addition, this project has a social significance, namely, it will allow implementing the concept of infrastructure development in the Central and far Eastern regions of Russia. It is also worth noting the huge potential of this digital device as a system for collecting data useful for both the economic and military sectors of the Russian Federation.

\section{References}

1. The Ministry of Foreign Affairs of the Russian Federation: News- URL: https://www.mid.ru/en/search?p $\mathrm{p}$ id $=3 \& \mathrm{p} p$ lifecycle $=0 \& \mathrm{p} p$ state $=$ maximized\&p p mode $=$ view\& 3 struts action $=\% 2$ Fsearch $\% 2$ Fsearch

2. Federal State Statistic Service (Rosstat). Russian Statistical Yearbook 2019, 371-372 (2019)

3. Russian Railway (RJD) : Statistics (2020) URL: http://eng.rzd.ru/statice/public/en?STRUCTURE ID=4

4. Russian Railway (rjd) - RZD Holding is working to create a unified information system which combines different modes of transport (2019) http://eng.rzd.ru/newse/public/en?STRUCTURE ID=15\&layer $\mathrm{id}=4839 \& \mathrm{id}=107085$ (08.03.19)

5. I.M. Zaychenko, O.V. Kalinina, S.S. Gutman Proceedings of the 28th International Business Information Management Association Conference - Vision 2020: Innovation Management, Development Sustainability, and Competitive Economic Growth. 758-767 (2016)

6. O. Kalinina, L. Alekseeva et al., E3S Web of Conferences 110, 02103 (2019) 
7. The Ministry of Economic Development of the Russian Federation (2020): News. URL:http://old.economy.gov.ru/en/home/press/news/201829012

8. Unified procurement information system in Russia. http://www.ved.gov.ru/eng/events/

9. H.R. Andrian, N.B. Kurniawan A Systematic Literature Review (2018) DOI: $10.1109 /$ ICITSI.2018.8695939

10. .V. Klechikov, M.M. Pryanikov, A.V. Chugunov. International Journal of Open Information Technologies. 12, 123-130 (2017)

11. Newspaper Transport of Russia - Keys to the Arctic (2019) Retrieved June 25, 2019, from http://press.rzd.ru/smi/public/ru?STRUCTURE_ID=2\&layer_id=5050\&id=3 $\underline{06946 .}$

12. China Merchants China Commerce \& Logistics Corporation CJSC 2018; AMSA (2015), from http://www.cmhk.com/main/a/2016/a26/a30448_30530.shtml

13. Arctic Council. (2016). Arctic Marine Shipping Assessment November 25, 2016 Report. 